Journal of Current and Advance Medical Research

July 2017, Vol. 4, No. 2, pp. 53-57

http://www.banglajol.info/index.php/JCAMR

ISSN (Print) 2313-447X

ISSN (Online) 2413-323X

DOI: http://dx.doi.org/10.3329/jcamr.v4i2.36356

ORIGINAL ARTICLE

OPEN ACCESS

\title{
Mammographic Evaluation of Breast Mass \& Comparison with Histopathological Findings
}

\author{
Lovely Yesmin ${ }^{1}$, Rued Hossain ${ }^{2}$, Bibekananda Haldar ${ }^{3}$, Mohammad Sazzad Hossain ${ }^{4}$, \\ Sajida Nahid $^{5}$, Kazi Shantono Saiham ${ }^{6}$, Nusrat Jahan ${ }^{7}$
}

\begin{abstract}
${ }^{1}$ Medical Officer, Department of Radiology \& Imaging, National Institute of Traumatology \& Orthopedic Rehabilitation, Dhaka, Bangladesh; ${ }^{2}$ Professor \& Head, Department of Radiology \& Imaging, Sir Salimullah Medical College, Dhaka, Bangladesh; ${ }^{3}$ Associate Professor, Department of Radiology \& Imaging, Sir Salimullah Medical College, Dhaka, Bangladesh; ${ }^{4}$ Assistant Professor, Department of Radiology \& Imaging, Sir Salimullah Medical College, Dhaka, Bangladesh; ${ }^{5}$ Radiologist, Department of Radiology \& Imaging, Dhaka Medical College \& Hospital, Dhaka, Bangladesh; ${ }^{6}$ Consultant, Doctors Care General Hospital \& Diagnostic Center, Brahmanbaria, Bangladesh; ${ }^{7}$ Medical Officer, Department of Radiology \& Imaging, Sir Salimullah Medical College \& Mitford Hospital, Dhaka, Bangladesh
\end{abstract}

[Reviewed: 30 February 2017; Accepted on: 1 April 2017; Published on: 1 July 2017]

\section{Abstract}

Background: Mammography is used for the detection of breast cancer. Objective: The purpose of the present study was to evaluate the diagnostic performance of Mammography in the diagnosis of benign and malignant breast mass. Methodology: This cross-sectional type of study was carried out in the Radiology \& Imaging department of Sir Salimullah Medical College and Mitford Hospital, Dhaka, during July 2013 to June 2015. Patients clinically suspected as having breast mass, referred in the above mentioned hospitals and enrolled for surgical management were included in this study. Mammography were done in all these patients and they were followed up from the admission up to the post-operative tissue diagnosis of breast mass in respective pathology departments for histopathological correlation. Results: A total of 41 patients had mass among them, 3(7.3\%) cases were malignant and 38(92.7\%) cases were benign patients. Histopathological diagnosis of invasive ductal carcinoma, invasive lobular carcinoma and medullary carcinoma were $8(14 . \%), 4(7.00 \%)$ and $1(1.8 \%)$ respectively. Mammography malignant was found 14 cases out of which $10(76.9 \%)$ malignant and $4(9.1 \%)$ benign evaluated by histopathology. Mammography benign was found 43 cases out of which $3(23.1 \%)$ malignant and $40(90.9 \%)$ benign evaluated by histopathology. The sensitivity was $76.9 \%$, specificity $90.9 \%$, accuracy $87.7 \%$, positive predictive values $71.4 \%$ and negative predictive values $93.0 \%$ in mammography. Conclusion: Mammography is highly sensitive, specific, reliable and useful method in the differentiation of malignant and benign breast masses. [Journal of Current and Advance Medical Research 2017;4(2):53-57]

Keywords: Mammographic evaluation; breast mass; histopathological findings; breast cancer; test validity

Correspondence: Dr. Lovely Yesmin, Medical Officer, Department of Radiology \& Imaging, National Institute of Traumatology \& Orthopedic Rehabilitation, Dhaka, Bangladesh; Email: labonno17@gmail.com; Cell no.: +8801911318715

Cite this article as: Yesmin L, Hossain R, Haldar B, Hossain MS, Nahid S, Saiham KS, Jahan N. Mammographic Evaluation of Breast Mass \& Comparison with Histopathological Findings. Journal of Current and Advance Medical Research 2017;4(2):53-57

Conflict of Interest: All the authors have declared that there was no conflict of interest.

Funding: This research project was not funded by any group or any institute on.

Contributions to authors: Yesmin L, Hossain R have contributed in protocol preparation, data collection, analysis and report writing. Haldar B, Hossain MS, Nahid S, Saiham KS, Jahan N have written the manuscript and have revised the manuscript.

Copyright: (92017. Yesmin et al. Published by Journal of Current and Advance Medical Research. This article is published under the Creative Commons CC BY-NC License (https://creativecommons.org/licenses/by-nc/4.0/). This license permits use, distribution and reproduction in any medium, provided the original work is properly cited, and is not used for commercial purposes. 


\section{Introduction}

Breast cancer is one of the common diseases among the females in the world. Generally about $25 \%$ of woman's are affected by breast cancer, in that $20 \%$ leads to lethal cancers ${ }^{1}$. It is one the leading cause of death due to cancer in women. Lesions of the breast are mainly confined to the female. In female complex breast structure and extreme sensitivity to endocrine influences predispose to a number of pathologic conditions. Most disease of breast present as palpable lumps, inflammatory lesions, nipple secretions or mammographic abnormalities ${ }^{2}$. The common causes of breast lumps include inflammatory, traumatic (haematoma. fat necrosis), cystic and neoplastic (benign and malignant). Among these the common causes of breast masses are fibroadenoma, fibrocystic disease and carcinoma. ${ }^{3}$ Breast carcinoma is the most common cancer among women between 40 to 55 years of age. Common forms of breast cancer are medullary carcinoma, mucinous carcinoma, tubular carcinoma, and inflammatory breast cancer, Paget's disease of the nipple, phylloides tumor, lipoma and galactocele ${ }^{4}$.

Mammography has been the "gold standard" in breast cancer detection for $>40$ years. Limitations in its ability to detect both small and lobular breast cancers, poor resolution in dense breasts, and a lack of significant improvement in cancer detection, despite digital mammography and computer aided diagnosis, has inevitably lead to a search for other modalities to improve the detection of breast cancer ${ }^{5}$. Generally Mammography became a reliable diagnostic tool in 1950s when industrial grade $\mathrm{x}$-ray film was introduced. And they are finding the breast cancer problems in two way, these are screening mammography is used as a preventive measure for women who have no symptoms of breast disease, diagnostic mammography involves additional X-rays of the breast to provide different views of the doubted region ${ }^{1}$. Although it is seen as the best examination technique for the early detection of breast cancer reducing mortality rates by up to $25.0 \%$, their interpretation requires skill and experience by a trained radiologist ${ }^{6}$.

Women who present with breast symptoms or who have palpable findings on clinical examination are usually investigated with breast imaging, which generally consists of mammography or breast sonography or both. The choice of primary breast imaging in examining women with symptoms is partly based on age. However, despite the importance of age in clinical practice, little evidence exists as to the appropriate age (or age range) that delineates the choice of initial diagnostic breast imaging in symptomatic women. In the absence of evidence, experts suggest that women younger than 35 years be examined with sonography, and women 35 years and older be examined with mammography, as the primary breast imaging modality ${ }^{7}$.

A comprehensive review of the literature found little evidence about the comparative age-specific accuracy of mammography and breast sonography in symptomatic women ${ }^{8}$. A study has subsequently provided the first empiric evidence regarding the comparative sensitivity of both imaging tests in symptomatic women who underwent both examinations. That study found that sonography was more sensitive than mammography in women younger than 62 years, the so-called crossover age, and mammography was more sensitive than sonography in women older than 62 years. However, the study's authors acknowledged that the nonindependent interpretation of the two tests and the analysis used may have led to underestimation of the sensitivity of mammography, and that the crossover age may be as early as 48 years ${ }^{9}$. For a valid comparison of the accuracy of two tests, the tests need to be interpreted independently without knowledge of each other in the same subjects ${ }^{10}$. The purpose of the present study was to evaluate the diagnostic performance of mammography in the diagnosis of benign and malignant breast mass.

\section{Methodology}

This present cross-sectional study was carried out among 60 patients referred for mammography with a clinical suspicion of breast mass to Radiology and Imaging Department of Sir Salimullah Medical College and Mitford Hospital, Dhaka during the periods of July 2013 to June 2015. All these patients were evaluated with detailed history and clinical examination then underwent mammography of the breast. Out of 60 patients 3 were excluded due to non availability of histopathology report or refused to do biopsy or surgical procedure. Finally 57 patients were included in analysis. Histopathology reports were collected and then compared with mammographic findings. Data were collected in a pre-tested questionnaire by taking history, examining the patients clinically, the finding and interpretation of the Mammography. Histopathological diagnoses were considered as gold standard of diagnostic criteria. The data were collected by the researcher herself. Statistical analyses were carried out by using the Statistical 
Package for Social Sciences version 20.0 for Windows (SPSS Inc., Chicago, Illinois, USA). The quantitative observations were indicated by frequencies and percentages. The mean values were calculated for continuous variables. For the validity of study outcome, sensitivity, specificity, accuracy, positive predictive value and negative predictive value of the mammography diagnosis evaluation of breast mass was calculated. $\mathrm{P}$ values $<0.05$ was considered as statistically significant. The women was escorted to the changing room, where she was undressed from the waist up and change into the screening center gowns after taking proper history and clinical examination. She was asked to wipe off any deodorants, perfumes or powders that she had used that day, as these can mimic micro calcification on the film. The peak $\mathrm{kv}$ used for mammogram was low of kvp of around $24-30 \mathrm{kv}$ and $\mathrm{mAs}$ varies depending on the breast tissue density. All mammogram were done using the film screen technique and consist of at least 2 views for each breast (CC \& MLO). Supplemental views were obtained when considered necessary for adequate visualization. Markers were used to indicate the side and view demonstrated on that particular film. This was done for a reference point to understand the orientation of the breast, especially in the $\mathrm{CC}$ view. Compression paddle was handled carefully to reduce the discomfort level of the patient. After processing of film mammogram was viewed in optimum lighting condition. A powerful magnifying glass was used to get a better look at suspected pathology. Final interpretation of mammogram was taken with the help of radiologist of department of Radiology and Imaging (SSMCH). All patients were undergoing excision or biopsy of the mass lesion. Histopathological slides was prepared and examined in the department of Pathology of Sir Salimullah Medical College and Mitford Hospital, Histotopathological slides was interpreted by an experienced pathologist in the department of pathology, Sir Salimullah Medical College and Mitford Hospital.

\section{Results}

This cross sectional study was carried out in the Radiology and imaging department of Sir Salimullah Medical College, Dhaka from July 2013 to June 2015 after approval of ethical committee. During the study period 57 patients from 35 to 60 years of age, referred for mammographic evaluation of breast mass, which were further evaluated with histopathological findings. Mammographic findings were evaluated by the researcher and a senior Radiologist. Patients who underwent operation, histopathological reports were collected. Out of 60 patients, two patients refused to undergo operation and one patient lost histopathology report. Finally mammographic findings of 57 patients were compared with histological findings.

Table 1: Distribution of the Patients by Age $(\mathbf{n}=57)$

\begin{tabular}{|l|c|c|}
\hline Age Group & Frequency & Percentage \\
\hline 35 to 40 Years & 7 & 12.3 \\
\hline 41 to 45 Years & 10 & 17.5 \\
\hline 46 to 50 Years & 18 & 31.6 \\
\hline 51 to 55 Years & 13 & 22.8 \\
\hline 56 to 60 Years & 9 & 15.8 \\
\hline Mean \pm SD & \multicolumn{2}{|c|}{$47.8 \pm 6.4$} \\
\hline Range (Min-max) & $\mathbf{( 3 5}$ to $\mathbf{6 0})$ \\
\hline
\end{tabular}

Table 2: Distribution of the Patients by Mammographic Findings $(n=57)$

\begin{tabular}{|c|c|c|}
\hline Mammographic findings & $\begin{array}{c}\text { Frequenc } \\
\mathbf{y}\end{array}$ & Percentage \\
\hline \multicolumn{3}{|l|}{ Glandular pattern } \\
\hline $\begin{array}{l}\text { - Pre dominantly } \\
\text { glandular }\end{array}$ & 27 & 47.4 \\
\hline $\begin{array}{l}\text { - Mixed glandular and } \\
\text { fatty }\end{array}$ & 30 & 52.6 \\
\hline \multicolumn{3}{|l|}{ Number of lesion } \\
\hline - $\quad$ Single & 56 & 98.2 \\
\hline - Multiple & 1 & 1.8 \\
\hline \multicolumn{3}{|l|}{ Density } \\
\hline - Dense & 56 & 98.2 \\
\hline - $\quad$ Radio lucent & 1 & 1.8 \\
\hline \multicolumn{3}{|l|}{ Margin } \\
\hline - Well define & 36 & 63.2 \\
\hline - $\quad$ Spiculated & 9 & 15.8 \\
\hline - Ill define & 8 & 14.0 \\
\hline - Lobulated & 1 & 1.8 \\
\hline - Irregular & 3 & 5.2 \\
\hline Mass & 57 & 100.0 \\
\hline Perilesional halo & 13 & 22.8 \\
\hline Architectural distortion & 11 & 19.3 \\
\hline Calcification & 10 & 17.5 \\
\hline Skin \& nipple change & 10 & 17.5 \\
\hline Enlarged lymph node & 3 & 5.3 \\
\hline
\end{tabular}

Table 3: Distribution of the Patients by Mammographic Diagnosis $(\mathbf{n}=57)$

\begin{tabular}{|l|c|c|}
\hline $\begin{array}{l}\text { Mammographic } \\
\text { diagnosis }\end{array}$ & Frequency & Percentage \\
\hline Benign & $\mathbf{4 3}$ & $\mathbf{7 5 . 4}$ \\
\hline Firbroadenoma & 31 & 54.4 \\
\hline Fibrocystic disease & 5 & 8.8 \\
\hline
\end{tabular}




\begin{tabular}{|l|c|c|}
\hline Cyst & 4 & 7.0 \\
\hline Abscess & 2 & 3.5 \\
\hline Galactocele & 1 & 1.8 \\
\hline Malignant & $\mathbf{1 4}$ & $\mathbf{2 4 . 6}$ \\
\hline
\end{tabular}

Table 5: Distribution of the Patients by Histopathological Diagnosis $(n=57)$

\begin{tabular}{|l|c|c|}
\hline $\begin{array}{l}\text { Histopathological } \\
\text { Diagnosis }\end{array}$ & Frequency & Percentage \\
\hline Benign & $\mathbf{4 4}$ & $\mathbf{7 7 . 2}$ \\
\hline Firbroadenoma & 29 & 50.9 \\
\hline Fibrocystic change & 6 & 10.5 \\
\hline Abscess & 4 & 7.0 \\
\hline Cyst & 4 & 7.0 \\
\hline Galactocele & 1 & 1.8 \\
\hline Malignant & $\mathbf{1 3}$ & $\mathbf{2 2 . 8}$ \\
\hline $\begin{array}{l}\text { Invasive ductal } \\
\text { carcinoma }\end{array}$ & 8 & 14.0 \\
\hline $\begin{array}{l}\text { Invasive lobular } \\
\text { carcinoma }\end{array}$ & 4 & 7.0 \\
\hline $\begin{array}{l}\text { Medullary } \\
\text { carcinoma }\end{array}$ & 1 & 1.8 \\
\hline
\end{tabular}

Table 6: Comparison between Mammography with Histopathology $(n=57)$

\begin{tabular}{|l|c|l|c|} 
Mammogra & \multicolumn{2}{c|}{ Histopathology } & Total \\
phy & Malignant & \multicolumn{1}{c|}{ Benign } & \\
\hline Malignant & $10(76.9 \%)$ & $4(9.1 \%)$ & $\mathbf{1 4}$ \\
\hline Benign & $3(23.1 \%)$ & $40(90.9 \%)$ & $\mathbf{4 3}$ \\
\hline Total & $\mathbf{1 3}$ & $\mathbf{4 4}$ & $\mathbf{5 7}$ \\
\hline
\end{tabular}

Table 7: Sensitivity, Specificity, Accuracy, Positive and Negative Predictive Values of the Mammography Evaluation for Prediction of Breast Mass

\begin{tabular}{|l|l|}
\hline Parameters & Values \\
\hline Sensitivity & $76.9 \%$ \\
\hline Specificity & $90.9 \%$ \\
\hline Accuracy & $87.7 \%$ \\
\hline $\begin{array}{l}\text { Positive predictive } \\
\text { value }\end{array}$ & $71.4 \%$ \\
\hline $\begin{array}{l}\text { Negative predictive } \\
\text { value }\end{array}$ & $93.0 \%$ \\
\hline
\end{tabular}

\section{Discussion}

This cross-sectional type of study was carried out with an aim to determine the benign and malignant nature of breast mass by mammography and diagnosis of breast mass by histopathology and also to evaluate the diagnostic performance of mammography in the evaluation of benign and malignant breast mass in comparison to the histopathological findings.

In this present study, a total of 57 patients were included, among which almost one third (31.6\%) patients were age belonged to $46-50$ years. The mean age was found $47.8 \pm 6.4$ years with range from 35 to 60 years. Houssami et $\mathrm{al}^{11}$ and Nascimento et al $^{12}$ found that the mean age of subjects was $44.9 \pm 8.7$ years varied from 27 to 55 years and $49 \pm 12$ years varied from 37 to 61 years respectively, which are is consistent with the current study. Yunus et $\mathrm{al}^{13}$ showed the mean age was 48 years varied from $30-80$ years. The above findings are comparable with the current study. Out of 57 patients, 43(75.4\%) were benign lesions and only $14(24.6 \%)$ malignant lesions. Mammographic findings of 31(54.4\%) patients were firbroadenoma, $5(8.8 \%)$ were fibrocystic disease, $4(7.0 \%)$ were cyst, 2(3.5\%) were abscess, 1(1.8\%) were galactocele and 14(24.6\%) were malignant lesions. Firbroadenoma $12.7 \%$, simple cyst $4.8 \%$, Breast Abscess $1.2 \%$. Galactocele $1.2 \%$, Breast malignancies cases $18.1 \%^{14}$. In another study Nascimento et $\mathrm{al}^{13}$ found that $58.3 \%$ lesions were benign and $41.7 \%$ were malignant.

In this present study it was observed that 41 patients had only mass among them, 3(7.3\%) were malignant and $38(92.7 \%$ ) were benign patients. Six patients were mass with spiculation, among them all (100.0\%) were malignant patients. Five patients were mass with macro calcification, among them all (100.0\%) were benign patients. Two patients were mass with micro calcification, among them all $(100.0 \%)$ were malignant patients. Three patients were mass with spiculation, micro calcification and enlarged axillary lymph node, among them all (100.0\%) were malignant patients. In this current study it was observed that benign and malignant lesion were $44(77.2 \%)$ and $13(22.8 \%)$ respectively. Out of 57 patients, histopathological diagnosis of $29(50.9 \%)$ were firbroadenoma, 6(10.5\%) were fibrocystic change, $4(7.0 \%)$ were cyst, 4(7.0\%) were abscess and $1(1.8 \%)$ were galactocele. All of them are benign lesion of breast. Histopathological diagnosis of invasive ductal carcinoma, invasive lobular carcinoma and medullary carcinoma were $8(14.0 \%), 4(7.0 \%)$ and $1(1.8 \%)$ respectively. In Houssami et al. ${ }^{11}$ study reported that the histologic types of cancer in the 240 patients were invasive ductal $70.0 \%$, ductal in situ $14.0 \%$, invasive lobular $9.0 \%$, tubular $4.0 \%$, medullary $1.0 \%$, and other types $1.2 \%$ and no histology $0.8 \%$. Biopsies of 115 breast masses detected at mammography were performed by Nascimento et $\mathrm{al}^{12}$ and found sixty- 
seven of these lesions (58.3\%) were benign and 48 $(41.7 \%)$ were malignant.

In this series out of all cases 14 were diagnosed as malignant breast mass by mammography, among them 10(76.9\%) were confirmed by histopathology. They were true positive. Four cases were diagnosed as having as malignant breast mass by mammography but not confirmed by histopathology. They were false positive. Out of 43 cases of benign breast mass which were confirmed by mammography, three $(23.1 \%)$ were confirmed as malignant breast mass and $40(90.9 \%)$ were benign breast mass by histopathological findings. They were false negative and true negative respectively. Nascimento et $\mathrm{al}^{12}$ found $58.3 \%$ and $41.7 \%$ lesions were benign and malignant respectively.

In this current study evaluation of breast mass by mammography showed that the sensitivity was $76.9 \%$, specificity $90.9 \%$, accuracy $87.7 \%$, positive predictive values $71.4 \%$ and negative predictive values $93.0 \%$. Houssami et $\mathrm{al}^{11}$ mentioned that mammographic sensitivity was $75.8 \%$. Mammography is nearly $87 \%$ accurate in detecting cancer $^{15-17}$ its specificity is $88.0 \%$ and its positive predictive value may be as high as $22.0 \%$. However, the false negative findings in mammography in evaluation of palpable breast mass is high, estimated between $4.0 \%$ and $12.0 \%{ }^{18}$. Nascimento et $\mathrm{al}^{12}$ mentioned in their study that the sensitivity was $68.0 \%$, specificity $76.0 \%$, and accuracy $75.0 \%$. NPV $76.0 \%$ and PPV was $51.0 \%$ observed by first observer. Another observed found sensitivity $87.0 \%$, specificity $44.0 \%$, accuracy $62.0 \%$, NPV was $83 \%$ and PPV $53.0 \%$ observed by second observer. Therefore, overall diagnostic accuracy correlates well with other studies.

\section{Conclusion}

It has been found that mixed glandular and fatty, single lesion, dense, and well defined margin are commonly found in mammography. Firbroadenoma is more common in benign lesion and invasive ductal carcinoma among the malignant lesions in histopathological diagnosis. Therefore it can be concluded that mammography is highly sensitive, specific and useful method in the differentiation of malignant and benign breast masses. It can be used to plan the subsequent appropriate management in majority of cases.

\section{Reference}

1. Abinaya S, Sivakumar R, Karnan M, Shankar DM, Karthikeyan M. Detection of breast cancer in mammograms-a survey. International Journal of Computer Application and Engineering Technology. 2014;3(2):1728

2. WHO. Cancer Registry Report: National Institute of Cancer Research and Hospital 2005-2007. National Institute of Cancer Research and Hospital, 2009;pp. 1-21.

3. Cotran RS, Kumar V, Robbins SL. The breast', In: Robbin's Pathological Basis of Disease, $6^{\text {th }}$ edition, W.B Saunders company, Philadelphia; 1999;pp. 1093-1114.

4. Imaginis. Advanced in mammography and other breast imaging methods, 2006; Available from http://www.imaginis.com/mammography/advances-inmammography-and-other-breast-imaging-methods-1

5. Malik SS, Akhter T, Malik SA. MammographicSonographic co-relation in the diagnosis of breast lump. Biomedica. 2008;24(2):147-51

6. Bovis K, Singh, S. Detection of Masses in Mammograms Using Texture Features. Proceedings of the International Conference on Pattern Recognition (ICPR'00), IEEE, 2000, pp. 267-270.

7. Dixon JM, Mansel RE. Symptoms, assessment, and guidelines for referral. In: Dixon JM, ed. ABC of breast diseases, $2^{\text {nd }}$ ed. London: BMJ, 2000, pp. 3-7.

8. Irwig L, Macaskill P. Evidence relevant to guidelines for the investigation of breast symptoms, Sydney, Australia: National Breast Cancer Centre, 1997, pp. 5-18.

9. Houssami N, Ciatto S, Irwig L, Simpson JM, Macaskill P. The comparative sensitivity of mammography and ultrasound in women with breast symptoms: an agespecific analysis. The Breast. 2002;11(2):125-30

10. National Health and Medical Research Council. How to review the evidence: systematic identification and review of the scientific literature', Canberra, A.C.T, Australia: Commonwealth of Australia, 2000, pp. 62-63.

11. Houssami N, Irwig L, Simpson JM, McKessar M, Blome S, Noakes J. Sydney Breast Imaging Accuracy Study: comparative sensitivity and specificity of mammography and sonography in young women with symptoms. American Journal of Roentgenology. 2003;180(4):935-40

12. Nascimento JH, Silva VD, Maciel AC. Accuracy of mammographic findings in breast cancer: correlation between BI-RADS classification and histological findings. Radiologia Brasileira. 2010;43(2):91-6

13. Yunus M, Ahmed N, Masroor I, Yaqoob J. Mammographic criteria for determining the diagnostic value of microcalcifications in the detection of early breast cancer. Journal-Pakistan Medical Association. 2004;54(1):24-8

14. Taori K, Dhakate S, Rathod J, Hatgaonkar A, Disawal A, Wavare P, Bakare V, Puri RP. Evaluation of breast masses using mammography and sonography as first line investigations. Open Journal of Medical Imaging. 2013;3(1):40

15. Osuch JR, Reeves MJ, Pathak DR, Kinchelow T. BREASTAID: clinical results from early development of a clinical decision rule for palpable solid breast masses. Annals of surgery. 2003;238(5):728

16. Berg WA, Campassi CI, Ioffe OB. Cystic lesions of the breast: sonographic-pathologic correlation. Radiology. 2003;227(1):183-91

17. Kolb TM, Lichy J, Newhouse JH. Comparison of the performance of screening mammography, physical examination, and breast US and evaluation of factors that influence them: an analysis of 27,825 patient evaluations. Radiology. 2002;225(1):165-75

18. Dennis MA, Parker SH, Klaus AJ, Stavros AT, Kaske TI, Clark SB. Breast biopsy avoidance: the value of normal mammograms and normal sonograms in the setting of a palpable lump. Radiology. 2001;219(1):186-91 